http://jmscr.igmpublication.org/home/ ISSN (e)-2347-176x ISSN (p) 2455-0450 crossref DOI: https://dx.doi.org/10.18535/jmscr/v8i12.05

\title{
A rare case of Radicular cyst associated with Dilacerated and Impacted Maxillary Central Incisor
}

\author{
Authors \\ Dr Rupesh Sharma ${ }^{1 *}$, Dr Dilbag Singh Thakur ${ }^{2}$ \\ ${ }^{1}$ Medical Officer Dental (Specialist) CHC Nalagarh District Solan Himachal Pradesh, India \\ ${ }^{2}$ Senior Resident Dermatology Pt. JLNGMC, Chamba, H.P., India \\ Institution: CHC Nalagarh District Solan Himachal Pradesh, India \\ *Corresponding Author \\ Dr Rupesh Sharma \\ Medical Officer Dental (Specialist) CHC Nalagarh District Solan Himachal Pradesh, India
}

\begin{abstract}
The maxillary incisors are very important for esthetics and body function of a person. there are several instances when the maxillary incisors either are delayed in erupting or totally fail to erupt. The unerupted tooth may be associated with various factors. Most common factors associated with impacted teeth include supernumerary teeth, odontoma, cysts, crown or root malformation, or ectopic development of tooth germ. But a Radicular cyst has been rarely reported with a dilacerated impacted maxillary central incisor. This case report presents the case of a 22 year old male patient with impacted permanent maxillary left incisor which was found to be inverted and also dilacerated at the cervical level after CBCT examination.A radiolucency was also appreciable around the crown. The case was surgically managed.

Keywords: Radicular cyst, Dilaceration, Impaction, Impacted tooth, Impacted Maxillary Central Incisor.
\end{abstract}

\section{Introduction}

Impacted teeth have been defined as those that have failed to erupt into the dental arch within the expected time frame. ${ }^{1}$ Tooth impaction is a frequent phenomenon, and the prevalence and distribution of this entity in different regions of the jaws may vary considerably. ${ }^{3}$ The third molars, maxillary canines, maxillary and mandibular premolars, and maxillary central incisors are the most commonly affected teeth. ${ }^{4}$ According to the literature, the prevalence of impacted tooth has been estimated to be between $8 \%$ and $38 \%$ in different countries, ${ }^{3,5,6}$ with a female predilection. ${ }^{7,8}$ An impacted tooth can result in carious lesions, infection, destruction of adjacent teeth, periodontal disease, and even oral and maxillofacial cysts or tumors. ${ }^{5}$ It has been found that cystic or neoplastic lesions arise in close proximity to the impacted tooth in $16 \%$ of cases, most commonly during the second and third decades of life. ${ }^{7}$

The first step in the diagnosis of Jaw lesions and orthopantomogram is mostly used as an initial imaging technique for the evaluation of impacted teeth. $^{5,9}$

The maxillary incisors are very important for esthetics and body function of a person. There are several instances when the maxillary incisors either are delayed in erupting or totally fail to 
erupt. The unerupted tooth may be associated with various factors. Most common factors associated with impacted teeth include supernumerary teeth, odontoma, cysts, crown or root malformation, or ectopic development of tooth germ. ${ }^{10,11}$ Among these dentigerous cyst is the most commonly reported factor. The frequency of maxillary central incisor impaction has been found in the range of $0.006 \%$ to $0.2 \% .^{12}$.

The dilaceration is characterized by an angulation in the crown and root of the tooth. This is often related to the trauma from the primary central incisors during the early developmental stages of the permanent central incisors. ${ }^{13}$ As per the best of our knowledge radicular cyst has been rarely reported with a dilacerated impacted maxillary central incisor.

This article presents the case of a 22 year old male patient with impacted permanent maxillary left incisor which was found to be inverted and also dilacerated at the cervical level after CBCT examination. A radiolucency was also appreciable around the crown. The case was surgically managed.

\section{Case Report}

A 22 year old male patient reported with a chief complaint of missing upper left front tooth. The patient was healthy and had no contributory medical history and no history of trauma in the upper front teeth region. There was a visible and palpable bulge in the labial vestibule in the region of clinically missing 21 . On initial panoramic radiographic examination an impacted tooth like structure was appreciable but could not diagnosed with conviction. So a cone beam computed tomography image (CBCT) was evaluated for confirmed diagnosis.

On CBCT examination the impacted permanent maxillary left incisor was found to be inverted and also dilacerated at the cervical level with an clearly appreciable radiolucent area around the crown. A dentigerous cyst considered in the provisional diagnosis of the radiolucent space present around the crown of the maxillary left permanent central incisor. The prognosis of the surgical exposure and forced central incisor was found to be poor because of the dilacerations present at the cervical level and also the inverted crown.

After confirmation of the poor prognosis the tooth was extracted. The extracted tooth had a cystic lesion around the crown as provisionally diagnosed which was enucleated along with the permanent maxillary central incisor. The surgical specimen measuring $0.8 \mathrm{~cm}$ was sent for histopathological examination. The patient remained asymptomatic after the surgery.

The histopathology report suggested cyst wall lined by hyperplastic non keratinised stratified squamous epithelium. The epithelium was corrugated at places and the cyst wall showed fibrosis, mild mixed chronic inflammatory infiltrate and hemorrhage. One of the foci showed hyaline eosinophilic structures of variable size and shape consistent with rushton bodies.

Overall features were suggestive of a radicular cyst. The histopathological diagnosis confirmed a maxillary anterior radicular cyst.

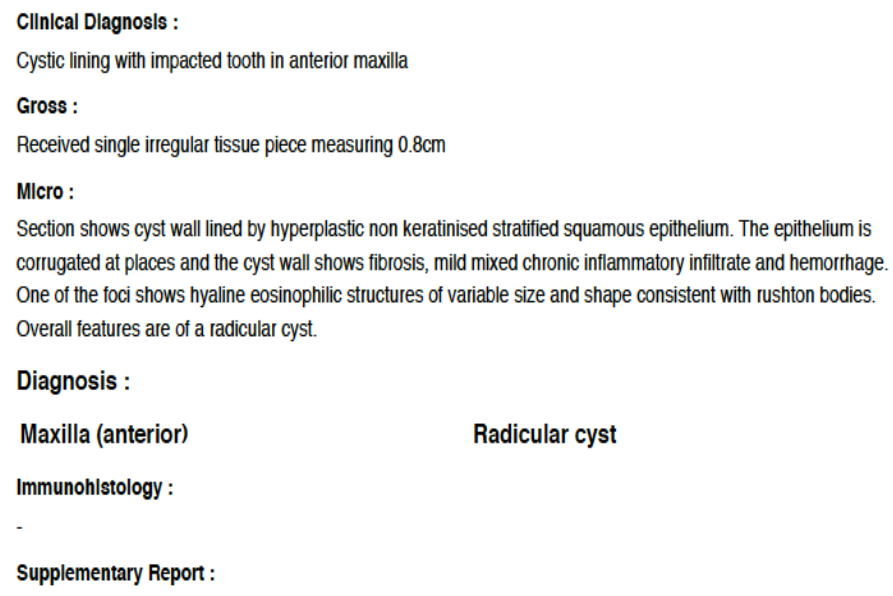

Figure 1 Histopathology Report

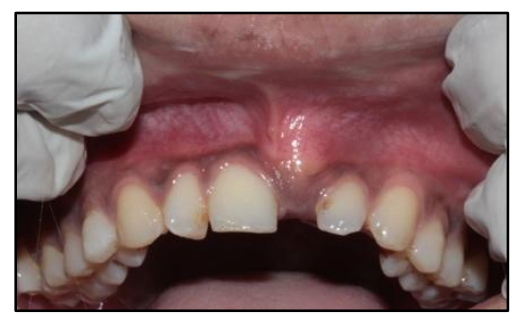

Figure 2 Clinical examination 




Figure 3 Surgical excision of the impacted tooth

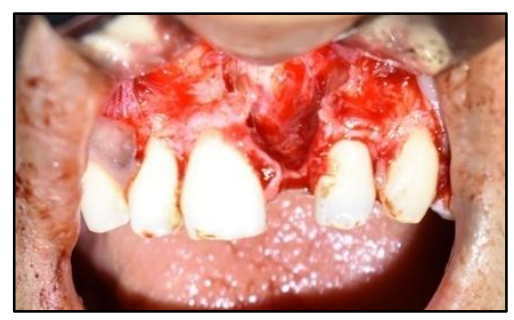

Figure 4 Cystic lesion Associated with the impacted tooth

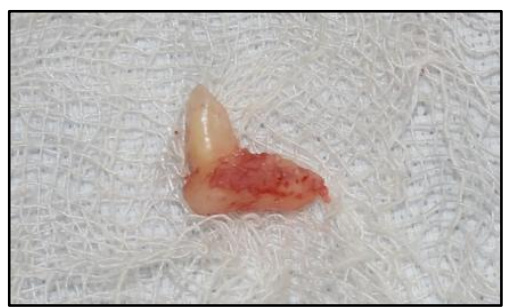

Figure 5 Surgically Excised tooth

\section{Discussion}

Impacted maxillary permanent central incisor due to dilaceration is rare and has serious impact on esthetics, phonetics, mastication, and psychology in young patients. The migration of the adjacent leading to the space is the most common reason for impaction of a permanent tooth. ${ }^{14}$ In this case, the clinical as well as radiographic examinations clearly showed that there was enough space available for the traction of the impacted maxillary left central incisor.

Depending on the localization and degree of dilaceration, a number of treatment options have been suggested. It is suggested that the success rate of dilacerated impacted tooth depends on the degree of dilaceration, position of the tooth, and the amount of root formation. ${ }^{15}$ In the present case the degree of dilacerations (at the cervical level), inverted crown and presence of a cystic lesion as evident from the combined clinical, radiographical and histopathlogical examinations made the prognosis of saving the permanent maxillary left central incisor very poor.

The possible explanation for the presence of a rare occurrence of a radicular cyst around the crown of permanent incisor could be the presence of an infected primary central incisor. ${ }^{16}$

Killian et al. have reported that trauma to the deciduous teeth can lead to odontogenic disturbances ranging from hypoplastic defects of crown to even cyst formation associated with the permanent tooth. ${ }^{17}$

\section{Conclusion}

Although the patient in this case gave negative history of any trauma or infection in the maxillary anterior teeth region, the only possible causes of a dilacerated and impacted permanent left central incisor with a radicular cyst could be the periapical inflammation due to infected deciduous maxillary incisor or a possible traumatic injury to the deciduous incisors which was not reported by the patient.

The impacted central incisor is a rare occurrence and may have ill effects on esthetics, speech, mastication, and psychology of the patient. There are a number of treatment modalities available in case of a dilacerated impacted tooth depending upon the location and degree of dilacerations. The most common treatment approach is the surgical exposure and orthodontic forced eruption of the impacted tooth when the prognosis is good, but if the prognosis of orthodontic management in poor it has to be surgically removed.

\section{References}

1. Juodzbalys G, Daugela P. Mandibular third molar impaction: review of literature and a proposal of a classification. J Oral Maxillofac Res. 2013;4:e1. [PMC free article] [PubMed]

2. Peterson LJ. Principles of management of impacted teeth. In: Peterson LJ, Ellis E III, Hupp JR, Tuker MR, editors. Contemporary oral and maxillofacial 
surgery. 3rd ed. St. Louis: MosbyYearbook Inc; 1998. pp. 215-248.

3. Chu FC, Li TK, Lui VK, Newsome PR, Chow RL, Cheung LK. Prevalence of impacted teeth and associated pathologiesa radiographic study of the Hong Kong Chinese population. Hong Kong Med J. 2003;9:158-163. [PubMed]

4. Bedoya MM, Park JH. A review of the diagnosis and management of impacted maxillary canines. J Am Dent Assoc. 2009;140:1485-1493. [PubMed]

5. Ahlqwist M, Gröndahl HG. Prevalence of impacted teeth and associated pathology in middle-aged and older Swedish women. Community Dent Oral Epidemiol. 1991;19:116-119. [PubMed]

6. Hugoson A, Kugelberg CF. The prevalence of third molars in a Swedish population. An epidemiological study. Community Dent Health. 1988;5:121-138. [PubMed]

7. Kruger E, Thomson WM, Konthasinghe P. Third molar outcomes from age 18 to 26 : findings from a population-based New Zealand longitudinal study. Oral Surg Oral Med Oral Pathol Oral RadiolEndod. 2001;92:150-155. [PubMed]

8. Santosh P. Impacted mandibular third molars: review of literature and a proposal of a combined clinical and radiological classification. Ann Med Health Sci Res. 2015;5:229-234.[PMC free article] [PubMed]

9. Mortazavi H, Baharvand M, Rahmani S, Jafari S, Parvaei P. Radiolucent rim as a possible diagnostic aid for differentiating jaw lesions. Imaging Sci Dent. 2015;45:253-261. [PMC free article] [PubMed]
10. Stewart DJ. Dilacerated unerupted maxillary central incisors. $\mathrm{Br}$ Dent $\mathrm{J}$. 1978;145:229-33

11. Andreasen JO. The impacted incisor. In: Andreasen JO, Petersen JK, Laskin DM, editors. Textbook and color atlas of tooth impactions. Diagnosis, treatment and prevention. Copenhagen: Munksgaard; 1997. pp. 113-24.

12. Grover PS, Lorton L. The incidence of unerupted permanent teeth and related clinical cases. Oral Surg Oral Med Oral Pathol. 1985;59:420-5. [PubMed]

13. Andreasen JO. Injuries to developing teeth. In: Andreasen JO, Andreasen FM, editors. Textbook and color atlas of traumatic injuries to the teeth. Copenhagen: Munksgaard; 1994. pp. 45794.

14. Duncan WK, Ashrafi MH. Management of the nonerupted maxillary anterior tooth. J Am Dent Assoc. 1983;106:6404.[PubMed]

15. Kuvvetli SS, Seymen F, Gencay K. Management of an unerupted dilacerated maxillary central incisor: A case report. Dent Traumatol. 2007;23:257-61. [PubMed]

16. Benn A., Altini M.Dentigerous cysts of inflammatory origin A clinicopathologic study Oral Surgery, Oral Medicine, Oral Pathology, Oral Radiology, and Endodontics, 1996, 81 (2), pp. 203-209

17. Killian CM, Leventhal PH, Tamaroff JL. Dentigerous cyst associated with trauma to a primary incisor: a case report. Quintessence Int 1992;23:683-6. 